\title{
Ways of Forming Personal and Social-Labour Functions of a Future Teacher
}

\author{
Nazira P. Tangkish ${ }^{1, \#, *}$, Yussubaly N. Kamalov ${ }^{1, \#, ~ G u l n u r ~ A r i p z h a n ~}{ }^{2, \#}$, \\ Hanzada Kairakbaeva ${ }^{1, \#}$, Gulnara Duisebaeva ${ }^{3, \#}$ and Ainur S. Erbota ${ }^{2, \#}$ \\ ${ }^{1}$ Department of Vocational Training, M. Auezov South-Kazakhstan State University, Shymkent, Republic of \\ Kazakhstan \\ ${ }^{2}$ Department of English Philology, Khoja Akhmet Yassawi International Kazakh-Turkish University, Turkestan, \\ Republic of Kazakhstan \\ ${ }^{3}$ Department of General Academic English, Khoja Akhmet Yassawi International Kazakh-Turkish University, \\ Turkestan, Republic of Kazakhstan
}

\begin{abstract}
Objective: The relevance of research is determined by the fact that it allows identifying the main criteria by which the development of a teacher is ensured both at the level of personal development and at the level of improving labour functions. The authors understand the complex development of personal and social-labour functions of a teacher as self-development in the process of fulfilling professional relations.

Background: Each of the participants in the educational process must meet the requirements set by state educational standards. With that, the personal qualities of a teacher should be fully correlated with the necessity of improving labour parameters.

Method: The effectiveness of the introduction of pedagogical conditions, which had a significant impact on the professional self-development of teachers, was tested experimentally with the use of anthropocentric and activity-based approaches to studying the problem, as well as with the use of the statistical method.

Results: The analysis presented in the paper showed that the indicated pedagogical conditions contribute to the formation of professional motivation, focus on the professional self-development of teachers, a high level of aspirations, awareness of the value of individual professional self-development, the ability to notice shortcomings, develop social skills and communication skills of teachers.

Conclusion: It was determined that the socio-psychological climate in an institution, where there is organisational support from the administration and informational support from other specialists, contributes to the development of operationalactivity and reflective and value-based components.
\end{abstract}

Keywords: Teacher, professional self-development, scientific and methodological work, motivation, teacher qualities.

\section{INTRODUCTION}

The teacher's personal qualities allow, in general, to implement the system requirements for the learning process. With that, the significance of the level of education at which this provision is implemented is not always taken into account. We consider the need for teachers to carry out their professional activities both at the level of school education and in higher educational institutions. In this context, a scientific position is important, which notes that by choosing a particular value, in this case, continuous professional selfdevelopment, a person forms a kind of long-term plan of behaviour and determines a long-term, meaningful perspective of activity [1]. Values determine the significance of phenomena, objects of reality, and

*Address correspondence to this author at the Department of Vocational Training, M. Auezov South-Kazakhstan State University, Shymkent, Republic of Kazakhstan; Tel: +87252210141; E-mail: imankulova5102-1@ubogazici.in

"These authors are equally contributed. culture from the standpoint of their compliance or noncompliance with the needs of society, social communities, groups, or an individual [2].

In light of the investigated issue of professional selfdevelopment of future special education teachers, a position that deserves attention is the position that determines such components of a teacher's professional values [3]:

- the goals of the teacher as a subject of professional and pedagogical activity;

- $\quad$ means of professional and pedagogical activity;

- the relations of the teacher as a subject of the professional pedagogical activity, which reveal the content and meaning of the relations as the main mechanism for the functioning of integral pedagogical activity;

- teacher's knowledge as a subject of the professional and pedagogical activity, which 
reveals the meaning and significance of psychological and pedagogical knowledge in the process of carrying out the pedagogical activity;

- the qualities of a teacher as a subject of the professional pedagogical activity, which reveal the content and meaning of personality traits, namely: individual, personal, communicative, professional qualities of a teacher, manifested in special abilities: for creativity, for designing personal activity.

The study of scientific and theoretical sources on the relevant issues gives grounds to determine the most significant values for special education teachers [4]. These include the following:

- humanistic values of pedagogical activity (uniqueness and individuality of the personality, personality development, its self-fulfilment);

- professional and moral values (kindness, compassion, mercy, sincerity, loyalty, professional duty, freedom, faith, trust, justice, patriotism, commitment, professional honour);

- the values of creative self-fulfilment (improvement of professional and creative abilities, the teacher's subject, constant selfimprovement of the teacher, the value of innovation);

- intellectual values (truth, professional knowledge, creativity, knowledge, free access to information);

- social values (professional and pedagogical communication, professional and pedagogical corporatism, collegiality, traditions, family, love, and affection for children);

- $\quad$ aesthetic values (beauty, harmony).

According to the proposed classification of values, the continuous professional self-development of future inclusive education teachers, of course, can be ranked among the values of creative self-fulfilment [5].

The main sources of professional self-development of teachers are: mainstreaming of the needs of teachers in professional self-development; information and communication technologies (video presentation of the results of professional self-development; scapcoaching; web conferences; portfolio of professional self-development; use of other Internet resources); development of the teacher's personal potential (teacher's professionally significant qualities, emotional, and volitional sphere, spiritual and moral qualities, etc.); psychological, pedagogical, and fiction literature; professional contests; the results of monitoring the success of the teacher; psychological support for the process of professional selfdevelopment of a teacher (informing; counseling; psychotherapy; motivational trainings); pedagogical readings with informal exchange of opinions; the Oxford Debate on Teacher Professional Development and Self-Development; schools of professional success (meetings with those teachers who have professionally and creatively fulfiled themselves, exchange of experience, professional and creative workshops).

One of the most effective means of improving the professional competence of teachers is self-education. Professional self-education of a teacher is a conscious activity to improve their personality as a professional: adapting their unique individual qualities to the requirements of the pedagogical activity, constantly improving professional competence, and continuously improving the qualities of their personality. And since teaching oneself is much more difficult than teaching someone else, it requires methodological support. It should be multi-level and necessarily gradual. Apart from the collective forms, the individual creative work of teachers also deserves approval, when teachers, while working on a problematic subject, prepare scientific and methodological manuals, which are noted in competitions of pedagogical creativity.

Active forms of methodological work are also widely used, which are designed to help the special education teacher improve the theoretical level, master new, more advanced methods and techniques of teaching and upbringing, the experience of the best teachers, and also contribute to their creative search, the growth of pedagogical skills. Thus, teachers' creative reports have become traditional at meetings of the methodological association and the methodological council, where teachers who are being certified share their findings, methodological developments, showcase other teachers the achievements of their personal experience. All this contributes to the improvement of the professional, methodological, and psychology and pedagogical levels of the teacher.

The purpose of the article is to identify the main criteria by which the development of an inclusive education teacher is ensured both at the level of 
personal development and at the level of improving labor functions.

\section{MATERIALS AND METHODS}

According to the anthropocentric approach, the personality of the teacher in a special education environment constitutes the object and subject of professional self-development. Furthermore, as evidenced by the research carried out, the subject's professional personal values determine the process of self-development [6]. The totality of personal and professional values determines the direction of the process of personality self-development, influencing the dynamics of its development, and is the main mechanism that determines self-development in all periods of personal and professional formation of an individual [7]. Personal and professional values affect the possible ways and means of self-development of an individual, forming goals, and an internal program for the process of its implementation [8].

The anthropocentric approach, which is based on philosophical, psychological, pedagogical anthropology, explains the significance of the individual value system in the life of an individual, namely: they build for themselves a system of guidelines, goals, ideals that determine the logic and dynamics of their life path; they themselves are responsible for the choice of their fate, their place in the world [9].

The anthropocentric approach is based on the following ideas [10]: the integrity and intrinsic value of the individual; spirituality of a person and the value of reflection for the development of their subjectivity; the unique ability of a person to determine moral values and guidelines for themselves; openness of a holistic pedagogical process aimed at creating conditions for a person's self-education, providing them with room for choice, identifying opportunities for free and creative activity [11]. In the centre of attention of representatives of the anthropocentric approach, the question arises about the modern goals and means of developing human abilities in the context of the teacher's professional self-development [12]. The formation of reflexive skills and focus on the professional selfdevelopment of the special education teacher is important [13].

One of the ways to form an inclusive education teacher as a competitive specialist is an activity-based approach, since mastering the structure and mastering the technology of professional activity induces the specialist's personality to self-organisation, selffulfilment, and self-control, which are important integral components of its professionalism [14]. The formation of the activity approach in pedagogy is closely related to the development of activity theory in psychology [15]. In the context of our research, the activity-based approach can be defined as such an organisation of the educational process where the future teacher acts from the standpoint of an active subject of cognition, in whom educational skills are purposefully formed in professional self-development, planning the goals of professional self-development activities, its implementation, and regulation, self-control in preparedness for professional self-development, analysis, and assessment of the results of personal activities [16].

Given this context, it should be emphasised that the activity-based approach, introducing its own characteristics of the goals and objectives of the pedagogical process, radically rebuilds its procedural and technological side in such a way that the subjects of the educational process master the activity in its holistic representation [17]. Thus, the teacher's personal involvement in the process of professional self-development underlies the basis of the activitybased teaching method, in which the components of the activity are directed and controlled by the teacher [18].

The effectiveness of the implementation of the pedagogical conditions outlined by us, which had a significant impact on the professional self-development of teachers, was tested experimentally [19]. The purpose of the educational experiment was to experimentally test the effectiveness of introducing pedagogical conditions for the professional selfdevelopment of teachers. The main stages of the educational experiment were: prognostic, organisational, and practical.

The prognostic stage of the educational experiment comprised the formulation of the goal, objectives, and main directions of its implementation. At this stage, the theoretical substantiation of the pedagogical conditions for the professional self-development of teachers was carried out. At the organisational stage, the main attention was paid to the justification and selection of the appropriate organisational and methodological support. To prepare for the practical stage of the educational experiment, an experimental group was determined. 
The practical stage of the educational experiment was carried out based on the experimental complex created by the authors, which preceded the author's special course, as well as personality-oriented forms of teaching theoretical material: lecture-discussion, lecture-press conference, lecture-dialogue; practical classes, which introduced innovative teaching methods (synectics method, method of a specific situation, method of projects, method of "brainstorming", method of creating a situation of interest, method of reliance on life experience), problem pedagogical situations were solved; psychological and pedagogical training were introduced; independent work (preparation of multimedia presentations, diverse types of scientific articles).

To verify the research, two groups of special education teachers were assigned, who formed, respectively, a control group (whose participants did not experience any formative influences) and an experimental group (in which a purposeful educational influence was carried out). The number of examined persons was 162. The participation of the respondent in the programme and, accordingly, the determination of belonging to a particular group was carried out with the use of random selection. The experimental testing factored in the strategies of scientific and methodological support for the professional selfdevelopment of teachers, namely:

1. Well-being strategy - the implementation of professional self-development by teachers in order to achieve relative peace, which is conditioned by a sense of physical and psychological safety.

2. A strategy for meeting basic needs at the rationalisation level - the teacher's aspiration to identify positive social manifestations, to achieve harmony with the outside world as a result of the implementation of the formula "I am doing everything right."

3. A strategy for achieving results - the teacher's orientation towards the end result, which can be determined both by their own goals and the tasks set personally and (or) professionally significant social environment. The consequences of their implementation of this strategy are: achievement of internal coherence or harmony with the outside world, professional self-fulfilment, life creation, adaptation to the conditions of professional activity, personal success, professional recognition, partnership, the achievement of professional results that will satisfy applicants for education and the administration of an educational institution, etc.

4. The strategy of success - setting up the teacher for a successful, positive result. This strategy is conditioned by the content that the teacher implies in the concept of "success" and often depends on the formation of their values and life priorities.

5. The strategy of partnership interaction is focused on the development of teachers' communicative competences, professional and personal qualities, which allow ensuring humanity, dialogicality, equality of teachers' relations with other subjects of the educational space.

6. The strategy of ensuring the integrity of the personality through the comprehension of selfdetermination - the implementation of the teacher's professional identification and selfidentification through the desire for personal integrity. The teacher's implementation of this strategy is resistant to the need for selfdevelopment, contributes to their entry into an integral system of self-development.

7. The strategy of balancing personal and professional qualities lies in the transformation of personality traits and professional qualities of teachers in the direction of balance. As a result of the implementation of this strategy, the teacher acquires emotional balance, transforms negative personality traits, and balances personal and professional qualities, contributing to their professional self-fulfilment and harmonisation of the educational space.

8. The strategy of restoration and enrichment of psychological and bioenergetic resources is the support of the mental, physical, and social health of teachers, which is based on the principle of conformity to nature.

9. The strategy of a meaningful and cognitive vision of oneself - the teacher's daily reflection on the problems of professional life, which is harmoniously connected with their holistic system of self-development (factoring in the ups and downs on the path to achieving the goals set by the teacher). 
Professional self-development of teachers was carried out in the following areas: the development of positive self-perception (the formation of positive thinking, the use of mental practices, affirmations, etc.); development of skills of motivational and targeted selfstimulation; mastering the methods and techniques of effective personally significant self-support; development of the qualities necessary for selfapproval in the process of professional activity; development of professionally significant qualities of teachers; development of the ability to enjoy the process and results of pedagogical activity.

The indicators of the effectiveness of the introduction of pedagogical conditions for the professional self-development of teachers in the motivational sphere were the numerical values of each of the integral components of readiness for professional self-development: operational-activity, need-motivational, reflexive and value-based and socio-communicative. The study assumed that the average group values for these components in the experimental group of teachers could significantly increase. Efficiency assessment was carried out with the use of the appropriate statistical criteria:

1. Student's t-test for independent samples. This criterion was used to assess the statistical significance of the differences between control and experimental samples. It was hypothesised that at the stage before the experiment, the average numerical values of the indicators of the components of the readiness of teachers for professional self-development are statistically indistinguishable in the control and experimental groups. Whereas after the experiment, the statistical differences between these groups should be significant. Accordingly, this criterion should indicate that in the experimental group of teachers, the level of components of their readiness for professional self-development has become higher than in the control group.

2. Student's t-test for paired (dependent) samples. It was intended to test the statistical significance of differences between dependent samples: the sample before the start of the experiment (both control and experimental) was compared with the sample after the experiment. It was assumed that there would be no statistically significant changes in the control group of teachers before and after the experiment, while in the experimental group, such changes would be recorded. Moreover, the vector of these changes will be described by an increase in the level of indicators of operational-activity, needmotivational, reflexive-value, sociocommunicative components.

It is advisable to note that for the educational influences to be considered effective, it is necessary to simultaneously meet the conditions, both according to the student's t-test for independent samples, and for paired samples. At the pre-experimental stage, no disagreements between the numerical indicators of the criteria of the experimental and control groups were found, which indicates the correct procedure for forming the composition of the groups. At the workshops, much attention was paid to such an important factor that contributes to the effectiveness of training as the ability of teachers to model the special education process in accordance with the modern requirements of pedagogical science and practice, to adapt it to the learning environment.

The subjects of the sessions were as follows: the use of design technology in the classroom; the specifics of teaching in accordance with the requirements of the state standard for basic and complete secondary education; development, testing, and implementation of educational technologies, innovative techniques in the educational process; the use of interactive learning technologies as a condition for the development of a creative personality; work with young teachers: student-centered learning; how to adapt modern techniques to the individual psychological features of students; communicative teaching method as one of the necessary prerequisites for the integration of society into the socio-cultural space; specific features of students' competence formation; optimal ways of developing basic activities in the classroom; activation of students' cognitive activity in the classroom; information and communication technologies in the classroom; portfolio as a modern form of presentation of pedagogical experience; stacking teaching and student with mental disorders portfolios; methodology for conducting a non-standard lesson; non-conventional forms and methods of work.

As a result of this study, the quality of training inclusive education teachers for conducting classes has improved, the scope of methods of teaching, development, and education has significantly expanded. Classes became clearer, more organised, and their practical orientation increased: the structure of the lesson became more flexible, mobile. 
Table 1: Algorithm of Professional Self-Development and Self-Fulfilment of Teachers in a Special Education Environment

\begin{tabular}{|c|c|c|}
\hline Step & Content & Result \\
\hline \hline Step I & self-perception & $\begin{array}{r}\text { unconditional self-perception (due to the formation of positive thinking and perception of the world, } \\
\text { human transformations at the emotional and mental levels of the personality) }\end{array}$ \\
\hline Step II & self-awareness & $\begin{array}{c}\text { search and disclosure of potential personal resources, creative possibilities and abilities, awareness } \\
\text { of personal life purpose; it is at this stage that a person searches for an answer to the question "How } \\
\text { to live with oneself in the conditions of a plurality of self-identifications and self-designations?" }\end{array}$ \\
\hline Step III & $\begin{array}{c}\text { spiritual mutual } \\
\text { enrichment }\end{array}$ & $\begin{array}{c}\text { at this stage, the teacher requires a Teacher (mentor, tutor, coach), interaction with whom contributes } \\
\text { to the mutual enrichment of professional psychological and pedagogical knowledge and practices } \\
\text { that contribute to self-development, self-improvement, and self-fulfilment of the individual, the } \\
\text { transformation of negative personality traits and personal qualities into positive ones, expanding the } \\
\text { scope of professional spiritual values }\end{array}$ \\
\hline Step IV & harmonisation & $\begin{array}{c}\text { harmonisation of the inner world of all subjects of the educational space takes place, which ensures } \\
\text { the process of harmonisation of the educational environment in which they find themselves }\end{array}$ \\
\hline
\end{tabular}

\section{RESULTS}

Our empirical research has shown the real state of readiness for professional self-development of teachers in a special education environment. In the course of the experimental work, a motivational-target algorithm for the professional self-development of teachers was developed, namely: the expansion of goals and motives; personal goal-setting (choice of goals); acquisition of personal value by professional goals; further professional self-development - a new stage (Table 1).

The summative stage of the educational experiment established certain components of the teachers' readiness for professional self-development, which need to be improved because their level constitutes the average population level [20]. These components were: operational-activity, need-motivational, reflexive, and value-based, socio-communicative.
Table 2 shows the results for the indicator of the operational-activity component. Upon comparison, statistically significant discrepancies $(p<0.05)$ were not revealed. After all, the operational-activity component primarily describes the degree of mastery of practical skills and abilities, readiness for professional tests is formed mainly in the educational process.

Table 3 reflects the results of the analysis of the effectiveness of certain pedagogical conditions in terms of the need-motivational component. The analysis of the results is reflected in the table, which shows that the program has succeeded in this aspect. Indeed, in the experimental group, the level of the needmotivational component increased by $11.4 \%$, and this was statistically significant at the level of $p<0.05$. As a result, there were discrepancies between the experimental and control groups, which were also statistically significant at the $p<0.05$ level. That is, the

Table 2: Results of the Analysis of the Effectiveness of Certain Pedagogical Conditions of Professional SelfDevelopment of Teachers in Terms of Operational-Activity Component

\begin{tabular}{|c|c|c|c|}
\hline & EG & Comparison & CG \\
\hline \hline Before experiment & $\mathrm{M}=33.033 \sigma=3.439$ & $\mathrm{t}=0.452 \mathrm{p}=0.653$ & $\mathrm{M}=33.933 \sigma=5.605$ \\
\hline Comparison & $\mathrm{t}=0.974 \mathrm{p}=0.338$ & & $\mathrm{t}=1.439 \mathrm{p}=0.161$ \\
\hline After experiment & $\mathrm{M}=33.933 \sigma=4.988$ & $\mathrm{t}=0.914 \mathrm{p}=0.365$ & $\mathrm{M}=32.733 \sigma=5.112$ \\
\hline
\end{tabular}

Table 3: Results of the Analysis of the Effectiveness of the Outlined Pedagogical Conditions of Professional SelfDevelopment of Teachers in Terms of the Need-Motivational Component

\begin{tabular}{|c|c|c|c|}
\hline & EG & Comparison & CG \\
\hline \hline Before experiment & $M=49.667 \sigma=6.266$ & $t=0.130 p=0.897$ & $M=49.400 \sigma=9.287$ \\
\hline Comparison & $t=2.383^{*} p=0.024$ & & $t=1.505 p=0.143$ \\
\hline After experiment & $M=55.333 \sigma=11.914$ & $t=2.010^{*} p=0.049$ & $M=49.733 \sigma=9.534$ \\
\hline
\end{tabular}


Table 4: Results of the Analysis of the Effectiveness of Certain Pedagogical Conditions of Professional SelfDevelopment of Teachers in Terms of the Reflexive and Value-Based Component

\begin{tabular}{|c|c|c|c|}
\hline & EG & Comparison & CG \\
\hline \hline Before experiment & $M=21.667 \sigma=2.339$ & $t=0.362 p=0.719$ & $M=21.400 \sigma=3.286$ \\
\hline Comparison & $t=3.146^{*} p=0.004$ & & $t=1.439 p=0.161$ \\
\hline After experiment & $M=24.000 \sigma=4.111$ & $t=2.610^{*} p=0.011$ & $M=21.467 \sigma=3.371$ \\
\hline
\end{tabular}

teachers showed an increase in professional motivation and focus on professional self-development, there is a high level of aspiration for self-education in professional activity.

Table 4 presents the analysis results for the indicator of the reflexive and value-based component. Considering the analysis of the results recorded in this table, it can be concluded that the applied educational influences contributed to an increase in the level of the components of the reflexive and value-based component. Thus, in the experimental group, the level of this component of teachers' readiness for professional self-development increased by $10.7 \%$, which was statistically significant at the level of $p$ $<0.05$. As a result, discrepancies between the experimental and control groups were identified, which were also statistically significant at the $p<0.05$ level. Thus, there is an increase in the level of awareness of the value of personal, professional self-development among teachers; they are inherent in the ability to analyse their activities as a professional adequately; they are capable of noticing the shortcomings and weaknesses in their own professional activities that impede professional self-development.

Table 5 illustrates the results of the analysis of the effectiveness of the implementation of the indicated pedagogical conditions for the professional selfdevelopment of teachers in terms of the sociocommunicative component. The analysis of the results of the experiment presented in the table shows that the pedagogical conditions, which were justified by authors in this aspect, succeeded. Indeed, in the experimental group, the level of the socio-communicative component increased by $9.6 \%$, which was statistically significant at the level of $p<0.05$. As a result, discrepancies between the experimental and control groups were recorded, which were also statistically significant at the $p<0.05$ level. Accordingly, there is reason to conclude that the introduction of the indicated pedagogical conditions has a positive effect on the professional self-development of teachers and allowed to increase the level of their social skills and communication skills in the experimental group.

Analysis of the results of the experiment showed that special education teachers began to better understand the essence of the concept of "professional self-development", well-mastered knowledge about the essence and components of professional selfdevelopment, and realised the need for its further formation. A survey of teachers confirmed the presence of positive changes. We received the following answers: "It seemed to me that I knew everything about myself and my profession, but while mastering the course, I realised that I still need to improve a lot"; "While mastering the course, I gained a lot of knowledge about my resource potential, career planning, conflict resolution, ways to improve my own self-esteem"; "Before, I didn't think about how to behave in a student classroom (walk, talk, organise my activities in the educational process), but now I know how to behave properly to be confident in myself"; "I never thought that a teacher needed skills of selfpresentation and self-management"; "I really liked the modelling of situations of the pedagogical activity, and also the ability to convince different types of parents". The generalised dynamics of changes in the

Table 5: Results of the Analysis of the Effectiveness of Certain Pedagogical Conditions of Professional SelfDevelopment of Teachers in Terms of Socio-Communicative Component

\begin{tabular}{|c|c|c|c|}
\hline & EG & Comparison & CG \\
\hline \hline Before experiment & $M=27.133 \sigma=3.997$ & $t=0.928 p=0.357$ & $M=25.967 \sigma=5.605$ \\
\hline Comparison & $t=2.917^{*} p=0.007$ & & $t=1.409 p=0.169$ \\
\hline After experiment & $M=29.733 \sigma=6.192$ & $t=2.332^{*} p=0.023$ & $M=26.133 \sigma=5.758$ \\
\hline
\end{tabular}




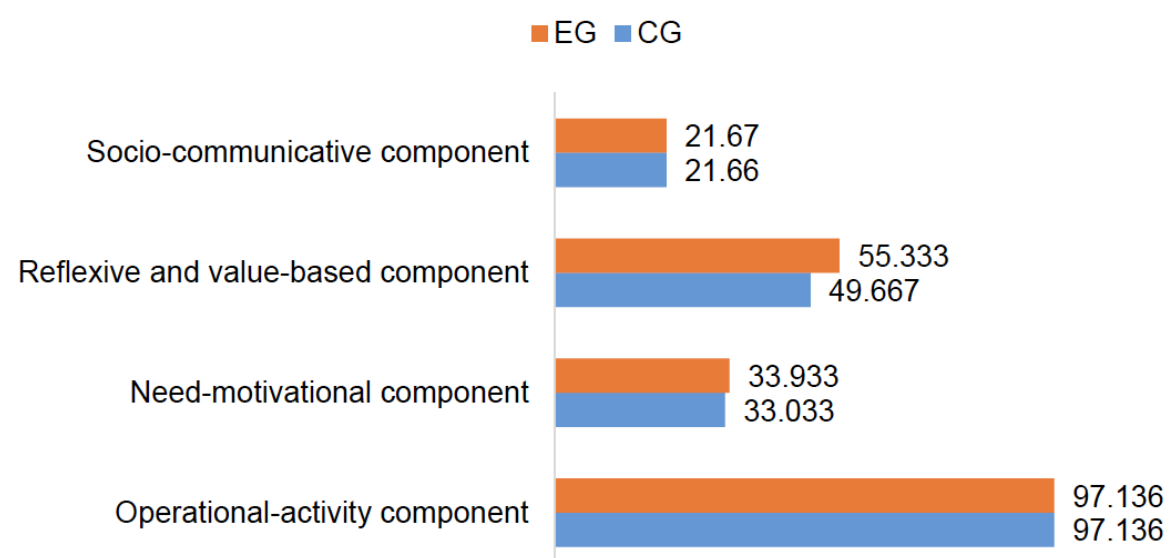

Figure 1: Readiness for professional self-development of teachers according to structural components.

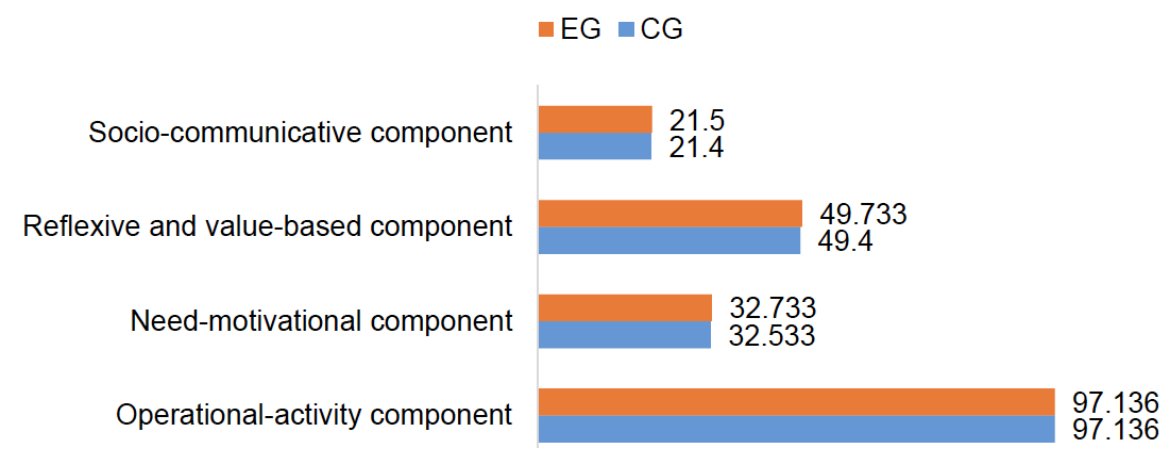

Figure 2: Indicators of components of professional self-development of teachers in the control group.

components of professional self-development of teachers are shown in Figures 1 and $\mathbf{2}$.

Consequently, our substantiation of the effectiveness of the influence of certain pedagogical conditions of professional self-development of teachers showed that the educational influence allowed to increase the level of such components of their professional self-development as need-motivational, reflexive-value, and socio-communicative. Thus, it was proved that the designated pedagogical conditions contribute to the formation of professional motivation, focus on the professional self-development of teachers, a high level of aspirations, awareness of the value of personal professional self-development, the ability to notice shortcomings, develop social skills and communication skills of teachers.

The results of the analysis of the effectiveness of the influence of the outlined pedagogical conditions of professional self-development of teachers according to the integral indicator are reflected in Table 6 and the diagram (Figure 3 ) and indicate that the distribution of teachers in the experimental group has changed according to the level of readiness for professional selfdevelopment. The indicators of high level increased, sufficient and low indicators significantly decreased. Whereas in the control group, where the authors did not exercise an educational influence, the results of the distribution of teachers' readiness for professional selfdevelopment in terms of the integral indicator did not change at all.

Thus, it was revealed that the vast majority of respondents associate the concept of "professional self-development" with the improvement of their personal "I", self-improvement, knowledge, dedication, motivation, communication skills, etc., while noting that the educational institution usually does not create the necessary conditions for professional self-development of teachers.

It was determined that the increase in the level of their professional self-development is associated with special education teachers with professional and personal development. According to teachers' subjective views, the self-development of a specialist is a continuous process, and the most important methods of forming readiness for professional self-development are self-education, conversation, self-education, and self-improvement. 
Table 6: The Results of the Effectiveness of the Outlined Pedagogical Conditions of Professional Self-Development of Teachers According to the Integral Indicator

\begin{tabular}{|c|c|c|c|}
\hline & EG & Comparison & CG \\
\hline Before experiment & $\begin{array}{c}\text { high }(n=4) \\
\text { sufficient }(n=15) \\
\text { low }(n=11)\end{array}$ & $\begin{array}{l}U e=437 \\
U c=338 \\
U e>U c \\
p=0.05\end{array}$ & $\begin{array}{c}\text { high }(n=4) \\
\text { sufficient }(n=16) \\
\text { low }(n=10)\end{array}$ \\
\hline Comparison & $\begin{array}{c}U e=279.5 \\
U c=338 \\
U e<U c ; \\
p=0.05\end{array}$ & & $\begin{array}{l}U e=424 \\
U c=338 \\
U e=U c ; \\
p=0.05\end{array}$ \\
\hline After experiment & $\begin{array}{c}\text { high }(n=11) \\
\text { sufficient }(n=16) \\
\text { low }(n=3)\end{array}$ & $\begin{array}{l}U e=308 \\
U c=338 \\
U e<U c \\
p=0.05\end{array}$ & $\begin{array}{c}\text { high }(n=4) \\
\text { sufficient }(n=18) \\
\text { low }(n=8)\end{array}$ \\
\hline
\end{tabular}

\section{$\because$ After experiment $\quad$ Before experiment}

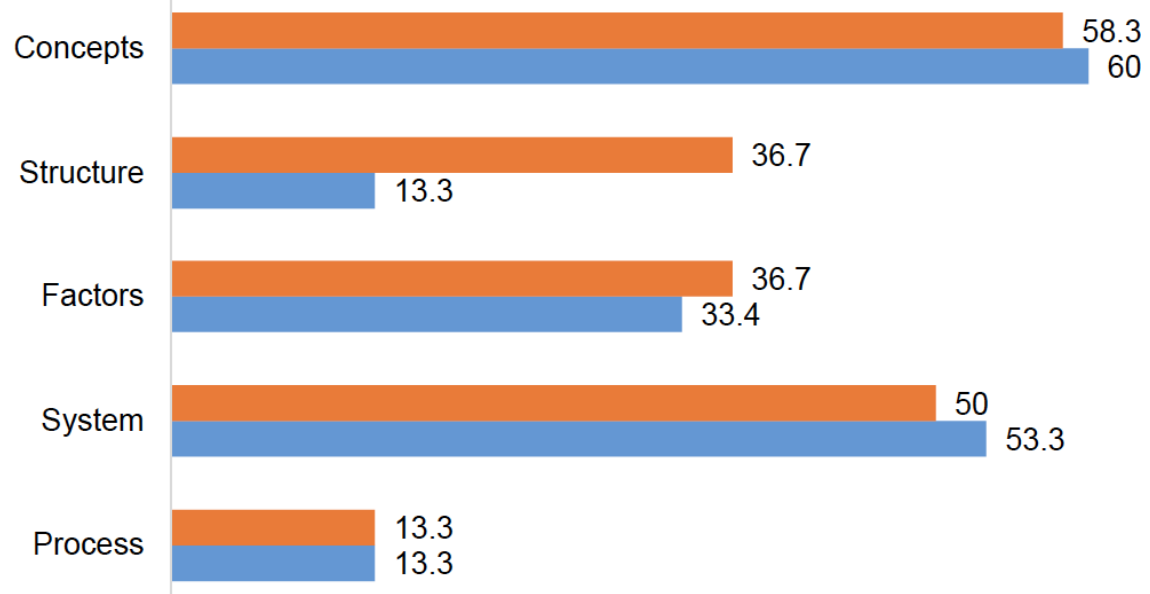

Figure 3: Distribution of teachers according to the levels of readiness for professional self-development

It was established that, according to their individual typological features, teachers are of a rational type. It is proved that the "I-concept" of teachers is quite developed - they believe in their strengths and abilities, energy, and independence, they tend to approve themselves. But these beliefs are highly dependent on external assessment. They are interested in themselves and are confident in their interest to others; however, the ability to self-government and selfunderstanding are considered such features that require further development.

\section{DISCUSSION}

In the conditions of the new educational paradigm, reoriented from the content of subject disciplines to the capabilities and needs of the person, the training of professional and pedagogical personnel of a new type becomes the most important condition for the revival of not only the educational space but also the domestic professional culture, its integration into universal and European culture. The professional and pedagogical competence of vocational education teachers ensures the expanded reproduction of the main social wealth professionals capable of creative self-determination and self-realization in their professional activities [17, 18].

The professional and pedagogical competence of the teacher of vocational training is formed, first of all, in the system of professional and pedagogical education in a higher educational institution. The 
success of university graduates' professionalpedagogical activity depends not only on the content of the learning process but also on the fulfillment of the personal and work functions of the future teacher of vocational training. In addition, the design of the implementation of the core competencies of the teacher of vocational training provides for the readiness of future teachers of vocational training for continuous professional and pedagogical education, the ability for scientific knowledge, the need for which is due to the increasing pace of development of science, restructuring of public consciousness and attitudes, changes in the content and methods of vocational training.

The modern policy of the Republic of Kazakhstan, especially the modernization of public consciousness, requires new thinking in the process of preparing teachers for vocational training. Due to these circumstances, a new type of vocational training has been formed. Thus, modern vocational and pedagogical education is regarded as one of the types of vocational education and is intended to ensure the readiness of graduates of higher vocational and pedagogical educational institutions to broadcast both universal and professional cultural values. This broadcast is based on the education of a humanistically oriented professional position of the future teacher of vocational training and his ability to solve problems in professional and pedagogical activity in training personnel $[19,20]$.

\section{CONCLUSIONS}

Thus, inclusive education teachers are described by an orientation towards defending their ideas, setting high goals for themselves, and striving to implement them. The level of formation of the professional and pedagogical orientation and the stability of interest in pedagogical activity have been determined, which guarantees the stability of motivation for further mastering the methods of pedagogical skill. It was found that teachers strive for self-development, their aspirations are based on self-assessment of their personal and professional qualities that contribute to self-development, as well as on the assessment of the project of pedagogical support as an opportunity for professional self-fulfilment. It was revealed that teachers' internal motivation prevails over external positive motivation and external negative motivation.

The operationalisation of theoretically grounded structural components of professional self-development was carried out, and a generalised personal profile of professional self-development of teachers was created. It was proved that the severity of such integral components of professional self-development of teachers as operational-activity, need-motivational, reflexive and value-based, and socio-communicative, is average, and severity of cognitive component is high.

It was found that stimulating factors had a greater impact on the professional self-development of teachers than those that hindered its formation and development. It has been established that the creation and provision of an atmosphere in which a special education teacher is able to become interested in the profession, gain recognition in the team and overcome certain obstacles associated with the limited information and other resources, will contribute to an increase in the level of the cognitive-cognitive component of professional self-development.

It was determined that the socio-psychological climate in an institution, where there is organisational support from the administration and informational support from other specialists, contributes to the development of operational-activity and reflective and value-based components. At the same time, the creation of pedagogical conditions in the educational environment, in which the teacher has the opportunity to gain recognition in the team and become interested in the pedagogical activity, reveals various aspects of the need-motivational component, and the creative and innovative environment in scientific and methodological work contributes to the development of the social and communicative component of the professional selfdevelopment of each teacher in a special education environment.

\section{REFERENCES}

[1] Pantić N. An exploratory study of teacher agency for socia justice. Teaching and Teacher Education 2017; 66: 219-230. https://doi.org/10.1016/j.tate.2017.04.008

[2] Li C-Y, Hou H-T, Chang K-E. Evaluation of pre-service teachers' technology acceptance of a mobile social networking App for teachers' professional development. In: Work-in-Progress Poster (WIPP): Proceedings of the 20th International Conference on Computers in Education, ICCE 2012. Singapore: Asia-Pacific Society for Computers in Education, 2012; pp. 68-71.

[3] Romero-López M, Pichardo MC, Bembibre-Serrano J, García-Berbén T. Promoting social competence in preschool with an executive functions program conducted by teachers. Sustainability 2020; 12(11): article number 4408. https://doi.org/10.3390/su12114408

[4] Ahrari S, Othman J, Hassan S, Samah BA, D'Silva JL. Role of social studies for pre-service teachers in citizenship education. International Education Studies 2013; 6(12): 1-8. https://doi.org/10.5539/ies.v6n12p1 
[5] Inan B. eacher revoicing in a foreign language teaching context: social and academic functions. Australian Journal of Teacher Education 2014; 39(9): 53-75. https://doi.org/10.14221/ajte.2014v39n9.5

[6] Youngblade LM. Peer and teacher ratings of third- and fourth-grade children's social behavior as a function of early maternal employment. Journal of Child Psychology and Psychiatry and Allied Disciplines 2003; 44(4): 477-488. https://doi.org/10.1111/1469-7610.00138

[7] Royo AG, Bautista A. Conservatory instrumental teachers' ideas about the functions and purposes of assessment. Foro de Educacion 2020; 18(1): 147-166. https://doi.org/10.14516/fde.651

[8] Hendrickx MMHG, Mainhard M, Boor-Klip HJ, Cillessen AHM, Brekelmans M. Social dynamics in the classroom: teacher support and conflict and the peer ecology. Teaching and Teacher Education 2016; 53: 30-40. https://doi.org/10.1016/j.tate.2015.10.004

[9] Ürey M, Çolak K, Yüzbaşioğlu BH, Kaymakci S. Comparison of prospective science and social studies teachers' knowledge levels of and misconceptions about atmospheric environmental problems. International Electronic Journal of Environmental Education 2020; 10(2): 216-236.

[10] Wentzel KR, Battle A, Russell SL, Looney LB. Social supports from teachers and peers as predictors of academic and social motivation. Contemporary Educational Psychology 2010; 35(3): 193-202. https://doi.org/10.1016/j.cedpsych.2010.03.002

[11] Warren AN. The social functions of teachers' beliefs in an online class. Teaching Education 2019; 30(1): 69-85. https://doi.org/10.1080/10476210.2018.1445217

[12] Theophilou E, Guxens A, Karageorgiev D, Beardsley M, Santos P, Hernández-Leo D. Soéle: a tool for teachers to evaluate social awareness in their learning designs. In: M. Scheffel, J. Broisin, V. Pammer-Schindler, A. loannou, J. Schneider (Eds.), EC-TEL 2019: Transforming Learning with Meaningful Technologies. Cham: Springer, 2019; pp. 761764.

https://doi.org/10.1007/978-3-030-29736-7_83
[13] Ebersöhn L, Loots T. Teacher agency in challenging contexts as a consequence of social support and resource management. International Journal of Educational Development 2017; 53: 80-91.

https://doi.org/10.1016/j.ijedudev.2016.11.005

[14] Jenkins LN, Fredrick SS, Wenger J. Peer victimization and social-emotional outcomes: The role of teacher and peer support. Aggressive Behavior 2018; 44(2): 176-184. https://doi.org/10.1002/ab.21741

[15] Englehart JM. Teacher perceptions of student behavior as a function of class size. Social Psychology of Education 2006; 9(3): 245-272. https://doi.org/10.1007/s11218-006-0007-3

[16] Akpinar M. Feedback strategies which social sciences teachers give to their students. Universal Journal of Educational Research 2018; 6(6): 1317-1327. https://doi.org/10.13189/ujer.2018.060623

[17] Chung T-Y, Chen Y-L. Exchanging social support on online teacher groups: Relation to teacher self-efficacy. Telematics and Informatics 2018; 35(5): 1542-1552. https://doi.org/10.1016/j.tele.2018.03.022

[18] Liu J. The study of relationship between students' perception to teacher's function and students' English learning achievement on the basis of multimedia application environment. BioTechnology: An Indian Journal 2014; 10(11): 5262-5270.

[19] Tennant JE, Demaray MK, Malecki CK, Terry MN, Clary M, Elzinga N. Students' ratings of teacher support and academic and social-emotional well-being. School Psychology Quarterly 2015; 30(4): 494-512. https://doi.org/10.1037/spq0000106

[20] Sakhieva RG, Majkova LV, Emelyanova MV, Gavrilova NG, Sharonova EG, Gatina AR, Pavlova NA, Baklashova TA. The supplementary education teacher's portfolio: essence, functions, structure and design principles. Mediterranean Journal of Social Sciences 2015; 6(2S3): 84-89. https://doi.org/10.5901/mjss.2015.v6n2s3p84

DOI: https://doi.org/10.6000/2292-2598.2020.08.03.14

\section{(C) 2020 Tangkish et al.; Licensee Lifescience Global.}

This is an open access article licensed under the terms of the Creative Commons Attribution Non-Commercial License (http://creativecommons.org/licenses/by-nc/3.0/) which permits unrestricted, non-commercial use, distribution and reproduction in any medium, provided the work is properly cited. 